\title{
O comportamento financeiro dos estudantes de graduação à luz da teoria dos prospectos
}

\section{The financial behaviour of students graduation in the light of the theory of prospects}

\author{
Jean Farias Martins ${ }^{1}$ \\ Talita Karolina Silva Dantas ${ }^{2}$ \\ Wiliana Silva Araújo ${ }^{3}$ \\ Manoel Pereira da Rocha Neto ${ }^{4}$ \\ Nilda Maria de Clodoaldo Pinto Guerra Leone ${ }^{5}$
}

\section{Resumo}

O estudo tem como objetivo geral replicar a investigação desenvolvida por Kahneman e Tversky (1979) identificando em estudantes do curso de graduação em Ciências Contábeis a evolução racional no processo de tomada de decisão ao longo dos diversos períodos, a que instituição de ensino pertenciam e a influência do gênero para as questões relacionadas às perdas e aversões aos riscos. Os achados da pesquisa revelam que os discentes do curso de ciências contábeis das duas instituições de ensino privadas analisadas utilizam uma série de fatores como os vieses cognitivos e emocionais na tomada de decisão que desenvolvem no contexto da Teoria dos Prospectos.

Palavras-chave: Finanças Tradicionais. Finanças Comportamentais. Teoria dos Prospectos.

\section{Abstract}

This study aims to replicate the research of Kahneman and Tversky (1979) identifying in the undergraduate program students in Accounting rational evolution in the

\footnotetext{
Mestre em Administração, Universidade Potiguar. E-mail: prof.jeanmartins@gmail.com

Contadora, Universidade Potiguar. E-mail: talitakarolina@hotmail.com

Contadora, Universidade Potiguar. E-mail: wilianasilva27@gmail.com

Doutor em Educação pela Universidade Federal do Rio Grande do Norte e docente do Mestrado Profissional em Administração da Universidade Potiguar- UnP. E-mail: walidbranco@gmail.com

5 Doutora em Ciências da Administração - Université de Grenoble II e Pós-Doc. em Ciências da Administração na Université de Savoie, Annecy, França. E-mail: n.leone@uol.com.br
} 
decision-making process over the different periods, to which educational institution owned and the influence of gender on issues related to losses and aversions to risk. The survey findings reveal that students of accountancy course of two private educational institutions analyzed using a number of factors such as cognitive and emotional biases in decision making that develop in the context of Prospect Theory.

Keywords: Traditional Finance. Behavioral Finance. Prospect Theory.

\section{Introdução}

As finanças tradicionais, quase em sua totalidade, foram erguidas a partir do arcabouço teórico da microeconomia neoclássica cujo alvo central é a racionalidade dos agentes econômicos. A racionalidade menciona que os investidores, após receberem informações do mercado são capazes de atualizarem de maneira correta as suas decisões no que se refere ao conceito de utilidade esperada subjetiva como apresentado por Savage (1964).

Este modelo é descrito pela Teoria da Utilidade Esperada (TUE), na qual os agentes são condicionados a tomarem decisões totalmente racionais, as pessoas possuem aversão ao risco e visam maximizar a utilidade. Contudo, as finanças comportamentais não concordam com essas afirmações. De acordo com Macedo e Fontes (2009), a visão racional das tomadas de decisão demonstrou várias dificuldades e inconsistências na medida em que os agentes econômicos incorporam outros vieses, tais como comportamentais, políticos sociais e ambientais.

Todos esses vieses cognitivos, de alguma forma, acabam interferindo na racionalidade ilimitada. O sentimento de obter lucros e a dor de se ter prejuízos são motivadores dos investimentos por parte dos agentes econômicos (investidores). As finanças modernas, denominadas de finanças comportamentais, buscam identificar e compreender a amplitude entre a irracionalidade e as decisões, partindo da premissa que no momento de se realizar um investimento o indivíduo sofre interferências políticas, sociais, ambientais e emocionais (GARCIA; OLAK, 2007). Esses estudos buscam entender o comportamento financeiro dos indivíduos, mesmo contra a racionalidade econômica, 
ou seja, em confronto com a teoria tradicional das finanças (ARAÚJO; TIBÚRCIO SILVA, 2006).

Os estudos, sobre as finanças comportamentais são estruturados na teoria dos prospectos (Prospect Theory), formulada por Kahneman e Tversky (1979). Eles foram os idealizadores dos estudos, contrapondo-se fortemente à teoria da racionalidade ilimitada, criando modelo descritivo em que mostram os agentes econômicos, ao tomarem decisões, são influenciados por heurísticas que as afastam da racionalidade.

De acordo com Cohen (1981 apud MACEDO Jr., 2003), os propensos investidores serão capazes de melhorar seus desempenhos desde que os agentes obtenham feedback específico em relação às decisões futuras. Portanto, esta pesquisa visa contribuir para auxiliar na compreensão dos comportamentos financeiros dos agentes, além disso, esclarece as falhas cognitivas às quais são sujeitas as pessoas, dessa maneira, contribuindo para melhor alocação de ativos.

Diante do exposto, até que ponto o gênero, o período e as instituições de ensino competem para que agentes emocionais não interfiram no processo de decisão? O estudo tem como objetivo geral replicar a investigação desenvolvida por Kahneman e Tversky (1979) identificando em estudantes do curso de graduação em Ciências Contábeis a evolução racional no processo de tomada de decisão ao longo dos diversos períodos, a que instituição de ensino pertencem e a influência do gênero para as questões relacionadas às perdas e aversões aos riscos.

Analisou-se inicialmente a capacidade de investimento por períodos e instituições distintas, em seguida, confrontou-se a capacidade de investimento entre os gêneros (masculino e feminino) e por fim compararam-se os resultados da hipótese já testada da pesquisa de Kahneaman e Tversky (1979) com a pesquisa atual. Dessa forma, foi possível avaliar a capacidade de investimento dos referidos discentes. Os achados da pesquisa revelam que as perspectivas comportamentais analisadas são influenciadas por sua racionalidade e sua cultura. 


\section{Finanças tradicionais}

A teoria tradicional financeira tem como fundamento o risco, sob a égide de investimentos ousados que tem papel fundamental neste estudo, uma vez que se trata de suposições irracionais. Este ensinamento tem suas premissas alicerçadas na teoria econômica neoclássica e baseia-se metodologicamente na teoria da utilidade esperada (TUE) a qual aborda o futuro e analisa os seus atuantes econômicos adequados para decidir à luz da racionalidade ilimitada, desconsiderando as aparências psicológicas da conduta do ser humano diante de decisões sob improbabilidade (THALER; MULLAINATHAN, 2000).

Ackert (2014), em seu estudo, faz uma comparação entre as finanças tradicionais e as finanças comportamentais e alerta que nas finanças tradicionais, a qual tem sido o paradigma dominante por várias décadas, os investidores fazem escolhas racionais que levam à maximização da utilidade esperada. A teoria da utilidade esperada por sua vez pressupõe que os indivíduos fazem suas escolhas em função do que eles querem, sabem e podem pagar, desprezando os aspectos cognitivos (comportamentais) relacionados ao processo de decisão. A referida autora discorre ainda acerca das questões que fundamentam as finanças tradicionais, ou seja, a teoria de decisão clássica, a racionalidade, a aversão ao risco, a teoria do portfólio, o modelo de precificação de ativos de capital e a hipótese do mercado eficiente e conclui que muitas das premissas associadas ao modelo tradicional são inválidas.

A racionalidade ilimitada é uma hipótese irracional que também é conhecida como "finanças antigas", em que as pessoas aplicam ativos sem medir os respectivos riscos e acomodam-se em não estimar o quanto o seu investimento é arriscado. Tais aplicações financeiras se originam de um rendimento maior que o do mercado. Com vieses neste fato, as finanças modernas relatam que as pessoas não podem ter rentabilidades superiores às do mercado ou de acordo com a condição de temeridade que o aplicador suporte. 


\section{Teoria moderna de finanças}

A teoria moderna de finanças aposta na busca da maximização da utilidade esperada, ou seja, a capacidade do indivíduo em medir as informações obtidas na aplicação dos recursos, e tomar decisões de acordo com suas expectativas racionais ao analisar a melhor proposição para a solução dos problemas financeiros, propiciando os menores riscos e a maiores retornos sobre o investimento (SÁ, 2007). Ou seja, é fundamentada em dados colhidos com base no raciocínio indeterminado dos indivíduos. O pressuposto dessa teoria baseia-se em função de agentes econômicos que são capazes de verificar qual melhor investimento, investigam as informações de modo racional, de forma a permitir formar um conhecimento acerca do ativo no qual se pretende investir.

Thaler e Mullainathan (2000) corroboram o entendimento predominante acerca da teoria moderna, ao afirmar que ela apresenta alicerces na teoria econômica neoclássica, segundo a qual pressupõe que o agente econômico toma decisão de modo racional e indeterminado, utilizando-se dos métodos de estrutura em consonância com a teoria da utilidade esperada, buscando defrontar as limitações. Por sua vez, a teoria das finanças comportamentais parte do pressuposto que alguns fenômenos financeiros podem ser plausivelmente entendidos a partir de modelos em que alguns agentes não são totalmente racionais. Isto é, observando-se os aspectos cognitivos associados à tomada de decisões financeiras.

Barberis e Thaler (2003) evidenciam dois blocos de estudos que merecem atenção. O primeiro no qual os autores denominam de limites à arbitragem, que defende que pode ser difícil para os comerciantes racionais desfazer os deslocamentos causados por comerciantes menos racionais; e por outro lado, a psicologia, que cataloga os tipos de desvios da racionalidade plena. Shefrin (2010) assegura que as finanças neoclássicas têm tantos pontos positivos quanto negativos. $O$ ponto positivo essencial é possuir hipóteses rigorosas. A principal fragilidade é 
confiar nos antecedentes dos agentes econômicos que atuam de modo racional e não refletem a realidade.

Há probabilidade que as aplicações de recursos de alto nível contenham erros maiores em sua capacidade de medir dados e de se tornar um erro gravíssimo, pois existem alguns fatores que influenciam na tomada de decisão para o investimento, tais como, por exemplo, o fator psicológico ou o otimismo excessivo que poderá induzir a fazer aplicações com falsas tendências de ganhos esperados, iludindo o investidor, fazendo com que ele deixe a racionalidade de lado e use a razão para simplificar o processo de decisão (VIEIRA, 2012).

Como crítica ao modelo tradicional ancorado nas teorias econômica e decorrente da consequente evolução do próprio comportamento financeiro do investidor surgiram as finanças comportamentais.

\section{Finanças comportamentais e a teoria dos prospectos}

As finanças comportamentais introduzem aos modelos de finanças tradicionais e modernos, a importância de se utilizar os instrumentos da psicologia e de se evidenciar os aspectos cognitivos inerentes ao processo decisório que envolve os investimentos financeiros muitas vezes com alto grau de riscos. Dessa forma, destaca-se a inserção de metodologias quantitativas, com experimento que estabelece uma amostra mais minuciosa da conduta humana nos mercados financeiros (MACEDO JR., 2003).

No campo de finanças comportamentais há uma mudança no seu estudo dia-a-dia, principalmente, por trazer derivados das finanças modernas que tomam como base os agentes econômicos na tomada de decisão e usando também a psicologia financeira das pessoas diante riscos. Segundo Shefrin (2010), o ponto positivo da teoria das finanças comportamentais é a busca por meio da psicologia em compreender o comportamento humano na parte financeira, trazendo a teoria muito mais perto da realidade. O primeiro estudo publicado em finanças comportamentais foi o de Kahneman e Tversky (2005), o qual analisa 
o comportamento de decisão das pessoas em meio a riscos nos investimentos. Este estudo deu origem à teoria dos prospectos em que as perdas são muito mais percebidas que os benefícios advindos dos ganhos. Em estudo anterior (KAHNEMAN; TVERSKY, 1979), os referidos autores comprovaram a racionalidade e as preferências excêntricas das pessoas que provém de um comportamento instável.

A partir do momento que o investidor tem a capacidade de assumir o risco do investimento, de forma segura, é possível saber quais são suas preferências e os objetivos a serem alcançados. Levando em consideração este raciocínio é provável que o investidor tenha o resultado esperado unindo suas preferências e a lógica racional. No entanto, é interessante que o investidor tenha a capacidade de assumir incertezas para obter resultados prováveis, podendo, assim, fazer a melhor escolha (FARIA, 2009). As finanças comportamentais representam a quebra dos paradigmas neoclássicos (SHEFRIN, 2010).

Há diferentes demarcações e percepções quanto à concepção de finanças comportamentais (VIEIRA, 2012). A maior parte das pesquisas, neste campo, apresenta-se de forma limitada, no estudo das ilusões cognitivas, em suas representações na conduta, no processo decisório e nos contornos que estas utopias podem intervir no mercado financeiro. Portanto, as Finanças Comportamentais, são rotineiramente determinadas como o bom emprego da psicologia, na tentativa de esclarecer as finanças diante as decisões financeiras dos indivíduos (OLIVEIRA; SILVA; SILVA, 2005).

Kahneman e Tversky (1979) apresentam ainda em seu estudo a função hipotética de valor da teoria dos prospectos (Figura 1) e tem a base fundamental tentar perceber a definição dos riscos das aplicações de recursos e suas estimativas. Em decorrência aos resultados alcançados em seu experimento, foi possível executar uma representação gráfica para descrever as atitudes comportamentais ao estimar aplicações de ativo, exemplificando a capacidade do risco, buscando a relação entre o ganho e a perda do investimento. 
Figura 1: Função hipotética de valor da teoria do prospecto

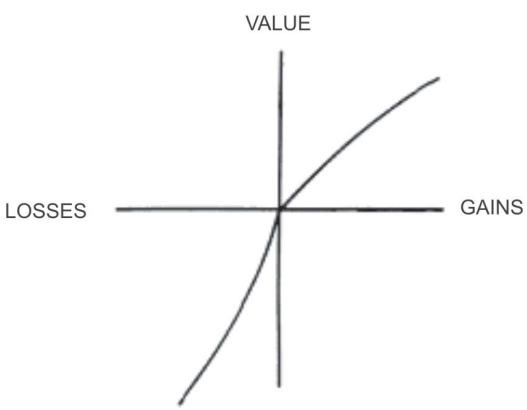

Fonte: Kahneman e Tversky (1979).

Trata-se, portanto, da tendência que os investidores têm em rejeitar um ganho maior por assumir uma possibilidade de perda relevante, ou seja, a grande maioria dos investidores tende a aceitar opções menos favorecidas, mas que oferecem maior probabilidade de ganho. Por se tratar de um modelo opcional da teoria da utilidade, esta teoria relata os valores dos indivíduos na tomada de decisão sobre a sua influência e não dos resultados esperados, ganho ou perda.

Essa teoria tem ajudado os estudiosos no auxílio de uma melhor percepção dos erros existentes nas decisões de cada indivíduo, além de entender como é importante a compreensão no processo de decisão, contendo uma base em relatos mais exatos no comportamento humano, em determinando ponto, em que há tomada de decisão no investimento (BAZERMAN, 2004).

Estudos averiguaram em suas análises que o comportamento financeiro dos estudantes com mais elevado nível de educação financeira foi idêntico ao de baixo grau de educação financeira, comprovando o alcance de aprendizado na prática, apoiando a utopia dos pesquisadores das finanças comportamentais (ROGERS; FAVATO; SECURATO, 2008). As implicações de certeza foram identificadas pelo método de verificar as eventualidades de um fato estimando como adequado, onde se proporcionavam exclusivamente prospectos aonde tem a capacidades de existir ganhos possíveis. 


\section{Método}

A pesquisa caracteriza-se como quantitativa e descritiva. Aplicouse como instrumento de coleta de dados um questionário estruturado com o propósito de replicar o estudo de Kahneman e Tvesky (1979). De acordo com o relato do método adotado pelos mencionados autores em seu experimento, as pessoas deveriam ser questionadas a tomar decisões em alternativa de hipotéticas de certezas e incertezas. A população alvo desta pesquisa foi composta pelos alunos de graduação Ciências Contábeis de duas instituições de ensino privadas, localizadas em uma mesma cidade na região nordeste do Brasil.

O questionário foi aplicado de forma aleatória aos alunos que se encontravam presentes em sala de aula no momento da sua aplicação e também disponibilizados em ambiente web para que pudessem ser respondidos virtualmente por meio de acesso a um link disponibilizado em laboratório cedido por uma das instituições de ensino. O diagnóstico, por sua vez, abrangeu três aspectos: a) os discentes foram segmentados por instituição de ensino (Instituição I e Instituição II); b) os discentes foram segmentados por períodos (segundo, quarto, sexto e oitavo); e c) os discentes foram segmentados por gênero (feminino e masculino). Foram aplicados questionários com 16 questões: as questões de número 1 a 8 , abordaram as possibilidades de ganhos com ou sem riscos de perdas; as questões de 9 a 12, demonstraram as possibilidades de perda com maiores ou menores prejuízos; e por fim, as questões de número 13 a 16 são indiferentes, e provocam o consequente efeito isolamento, em que a tendência é ter a mesma preferência, mesmo que a alternativa seja apresentada de forma diferente.

Obteve-se assim retorno de 273 questionários replicados, espontaneamente respondidos pelos alunos. Durante a aplicação foi orientado aos respondentes que não existiam respostas corretas, tendo visto que as alternativas derivavam de prioridades individuais. 


\section{Resultados da pesquisa}

Concluído o período de coleta de dados, aplicaram-se à base de dados os testes de Kruskal-Wallis (para a verificação por período e por grupo) e U Mann-Whitney (para verificação por gênero) observando se havia diferenças. Foram consideradas significativas as diferenças que possuíram o Asymp. Sig inferior a 5\%. Por último, confrontou-se os resultados obtidos com os achados por Kahneman e Tversky (1979), Cruz, Kimura e Krauter (2003) e Rogers et al. (2007).

Na Tabela 1, é possível observar os dados encontrados para as análises iniciais, por período e por instituição.

Tabela 1: Análise da frequência das respostas por período e por instituição.

\begin{tabular}{c|c|c}
\hline \multirow{2}{*}{ Questão } & $\begin{array}{c}\text { Frequência das respostas por } \\
\text { períodos }\end{array}$ & $\begin{array}{c}\text { Frequência das respostas por } \\
\text { Instituição (I e II) }\end{array}$ \\
\cline { 2 - 3 } & Asymp. Sig. & Asymp. Sig. \\
\hline 1 & $8,40 \%$ & $8,60 \%$ \\
2 & $60,50 \%$ & $40,40 \%$ \\
3 & $54,20 \%$ & $4,00 \%$ \\
4 & $49,20 \%$ & $18,10 \%$ \\
5 & $52,50 \%$ & $18,50 \%$ \\
6 & $34,90 \%$ & $95,30 \%$ \\
7 & $22,90 \%$ & $32,90 \%$ \\
8 & $47,40 \%$ & $10,70 \%$ \\
9 & $79,10 \%$ & $57,70 \%$ \\
10 & $21,10 \%$ & $1,30 \%$ \\
11 & $85,40 \%$ & $25,80 \%$ \\
12 & $54,50 \%$ & $38,40 \%$ \\
13 & $40,30 \%$ & $68,70 \%$ \\
14 & $12,60 \%$ & $38,10 \%$ \\
15 & $83,80 \%$ & $34,60 \%$ \\
16 & $36,40 \%$ & $83,80 \%$ \\
\hline
\end{tabular}

Fonte: Dados da pesquisa (2014).

Ao avaliar a frequência das repostas replicadas e usado o teste de Kruskal-Wallis não foi possível observar (nível de significância de 5\%), a mensuração em relação ao "p" valor com a disposição dos discentes ao risco, comparando os períodos em que os alunos se encontravam. Corroborando a descoberta de Rogers, Favato e Securato (2008), 
que alegam que os vieses no método cognitivo e perímetros a prática conserva-se mesmo em pessoas com grau de educação mais alta e instrução financeira mais estruturada.

Com relação à frequência por instituições depois de confrontadas, constatou-se que as questões 3 e 10 encontram-se abaixo do nível de significância de 5\%, apresentando um percentual de $4 \%$ no resultado da questão 3, o que significa $61,7 \%$ dos discentes da instituição I optaram pela alternativa $B$ (não oferece risco de perda e menos rentável), já os discentes da instituição II, 50,7\% escolheram alternativa A (maiores possibilidades de perda e mais rentável). Na questão 10 foi encontrado um percentual de $1,30 \%$ o que significa que os discentes da instituição I, 58,6\% optaram pela alternativa $\mathrm{A}$ (oferece menores chances de perder mais). Os discentes da instituição II, 56,4\% B (oferece maior chance de perder menos).

$\mathrm{Na}$ continuação, procurou-se observar se o gênero dos alunos influenciava a sua resposta. As frequências podem ser observadas na Tabela 2.

Tabela 2: Análise da frequência das respostas por gênero.

\begin{tabular}{l|c}
\hline \multirow{2}{*}{ Questão } & U de Mann-Whitney \\
\cline { 2 - 2 } & Asymp. Sig \\
\hline 1 & $30,70 \%$ \\
3 & $50,30 \%$ \\
4 & $85,70 \%$ \\
5 & $8,50 \%$ \\
6 & $59,90 \%$ \\
7 & $1,50 \%$ \\
8 & $6,20 \%$ \\
9 & $77,10 \%$ \\
10 & $27,10 \%$ \\
11 & $64,00 \%$ \\
12 & $54,20 \%$ \\
13 & $40,50 \%$ \\
14 & $59,30 \%$ \\
15 & $6,80 \%$ \\
16 & $47,10 \%$ \\
\hline
\end{tabular}

Fonte: Dados da pesquisa (2014). 
Em decorrência dos resultados demonstrados, observa-se que homens e mulheres, sucessivamente, permitem se comportarem da mesma maneira quando estimam perdas ou quando se sujeitam ao risco. Entretanto, ao serem avaliadas as respostas à questão $n^{\circ} 6$, disposta na Tabela 3, observam-se diferenças expressivas de percepção.

Tabela 3: Análise da frequência das respostas da questão $n^{\circ} 6$.

\begin{tabular}{l|c|c|c}
\hline \multirow{2}{*}{ Gênero } & \multicolumn{2}{|c|}{ Questão 6 } & \multirow{2}{*}{ Total } \\
\cline { 2 - 4 } & Alternativa A & Alternativa B & \\
\hline \multirow{2}{*}{ Masculino } & 51 & 67 & 118 \\
\cline { 2 - 4 } & $43,2 \%$ & $56,8 \%$ & $100 \%$ \\
\hline \multirow{2}{*}{ Feminino } & 45 & 110 & 155 \\
\cline { 2 - 4 } & $29 \%$ & $71 \%$ & $100 \%$ \\
\hline
\end{tabular}

Fonte: Dados da pesquisa (2014).

A questão $n^{\circ} 6$ procura examinar a aversão ao risco, pertinentes a ganhos financeiros, e apresentou que $35 \%$ dos discentes preferiram a alternativa A (que oferece um risco elevado), destes $43,2 \%$ eram do gênero masculino contra $29 \%$, feminino. Entre os $65 \%$ que optaram pela B (menor risco) 56,8\% eram homens e $71 \%$ eram mulheres. Corroborando o resultado alcançado na análise de Mineto (2005); Araújo e Tibúrcio Silva (2006), os quais apontavam que os entrevistados do sexo feminino ofereciam uma aversão maior ao risco quando realçados um rendimento.

Finalmente, os resultados encontrados da pesquisa atual foram comparados com os resultados encontrados no experimento conduzido por Kahneaman e Tversky (1979), obtendo-se os resultados demonstrados na Tabela 4. 
Tabela 4: Frequência dos prospectos na pesquisa e comparação com a pesquisa de Kahneaman e Tversky (1979).

\begin{tabular}{|c|c|c|c|}
\hline Questões & Alternativa & $\begin{array}{l}\text { Pesquisa } \\
\text { atual }\end{array}$ & $\begin{array}{c}\text { Kahneman } \\
\text { e Tversky } \\
(1979)\end{array}$ \\
\hline \multirow{2}{*}{1} & Resposta A :(\$2500:33\%; \$2400:66\%;\$0:1\%) & $18 \%$ & $55 \%$ \\
\hline & Resposta B:(\$2400:100\%) & $82 \%$ & $45 \%$ \\
\hline \multirow{2}{*}{2} & Resposta A:(\$2500:33\%;\$0:67\%) & $83 \%$ & $45 \%$ \\
\hline & Resposta B :(\$2400:34\%;\$0:66\%) & $17 \%$ & $55 \%$ \\
\hline \multirow{2}{*}{3} & Resposta A:(\$4000:80\%;\$0:20\%) & $20 \%$ & $45 \%$ \\
\hline & Resposta B:(\$3000:100\%) & $80 \%$ & $55 \%$ \\
\hline \multirow{2}{*}{4} & Resposta A:(\$4000:20\%;\$0:80\%) & $65 \%$ & $44 \%$ \\
\hline & Resposta B:(\$3000:25\%;\$0:75\%) & $35 \%$ & $56 \%$ \\
\hline \multirow{2}{*}{5} & $\begin{array}{l}\text { Resposta A: (Viagem de três semanas para } \\
\text { Inglaterra, França e Itália: } 50 \% \text {;Nada: } 50 \% \text { ). }\end{array}$ & $22 \%$ & $38 \%$ \\
\hline & $\begin{array}{l}\text { Resposta B: (Viagem de uma semana para a } \\
\text { Inglaterra:100\%) }\end{array}$ & $78 \%$ & $62 \%$ \\
\hline \multirow{2}{*}{6} & $\begin{array}{l}\text { Resposta A: (Viagem de três semanas para } \\
\text { Inglaterra, França e Itália: 5\%;Nada: } 95 \% \text { ). }\end{array}$ & $67 \%$ & $35 \%$ \\
\hline & $\begin{array}{l}\text { Resposta B: (Viagem de uma semana para } \\
\text { Inglaterra: } 10 \% ; \text { Nada: } 90 \%) \text {. }\end{array}$ & $33 \%$ & $65 \%$ \\
\hline \multirow{2}{*}{7} & Resposta A: (\$6000:45\%;\$0:55\%) & $14 \%$ & $33 \%$ \\
\hline & Resposta B: (\$3000:90\%;\$0:10\%) & $86 \%$ & $67 \%$ \\
\hline \multirow{2}{*}{8} & Resposta A:(\$6000:0,1\%;\$0:99,9\%) & $73 \%$ & $53 \%$ \\
\hline & Resposta B: (\$3000:0,2\%;\$0:99,8\%) & $27 \%$ & $47 \%$ \\
\hline \multirow{2}{*}{9} & Resposta A: (-\$4000:80\%;\$0:20\%) & $92 \%$ & $73 \%$ \\
\hline & Resposta B: (-\$3000:100\%) & $8 \%$ & $27 \%$ \\
\hline \multirow{2}{*}{10} & Resposta A: (-\$4000:20\%;\$0:80\%) & $42 \%$ & $51 \%$ \\
\hline & Resposta B: (-\$3000:25\%;\$0:75\%) & $58 \%$ & $49 \%$ \\
\hline \multirow{2}{*}{11} & Resposta A: (-\$6000:45\%;\$0:55\%) & $92 \%$ & $59 \%$ \\
\hline & Resposta B: (-\$3000:90\%;\$0:10\%) & $8 \%$ & $41 \%$ \\
\hline \multirow{2}{*}{12} & Resposta A: (-\$6000:0,1\%;\$0:99,9\%) & $30 \%$ & $45 \%$ \\
\hline & Resposta B: (-\$3000:0,2\%;\$0:99,8\%) & $70 \%$ & $55 \%$ \\
\hline \multirow{2}{*}{13} & Sim & $20 \%$ & $52 \%$ \\
\hline & Não & $80 \%$ & $48 \%$ \\
\hline \multirow{2}{*}{14} & Resposta A:(\$0:75\%;(\$4000:80\%;\$0:20\%):25\%) & $22 \%$ & $54 \%$ \\
\hline & Resposta B:(\$0:75\%;(\$3000:100\%):25\%) & $78 \%$ & $46 \%$ \\
\hline \multirow{2}{*}{15} & Resposta A:(\$1000:50\%;\$0:50\%) & $16 \%$ & $47 \%$ \\
\hline & Resposta B:(\$500:100\%) & $84 \%$ & $53 \%$ \\
\hline \multirow{2}{*}{16} & Resposta A:(-\$1000:50\%;\$0:50\%) & $69 \%$ & $62 \%$ \\
\hline & Resposta B:(-\$500:100\%) & $31 \%$ & $38 \%$ \\
\hline
\end{tabular}

Fonte: Dados da pesquisa (2014). 
Após a aplicação do teste Qui-Quadrado, ao nível de significância de $5 \%$, não foi constatado nenhuma diferença relevante no tocante à pesquisa inicial, existindo apenas uma acentuada diferença com relação às questões 1, 2, 6, 10, 13 e 14, em que, na pesquisa, atual é possível observar o quanto as decisões são racionais e a aversão ao risco fica clara, reflexo provavelmente de recentes experiências negativas dos entrevistados com investimentos em empreendimentos financeiros, tais como Telexfree, BBom Multiclick, Nnex, Priples e outros similares.

\section{Conclusão}

À luz da análise do referencial teórico relacionado às finanças comportamentais e da réplica da pesquisa seminal de Kahneman e Tversky (1979), constatou-se que os discentes do curso de Ciências Contábeis das duas instituições de ensino privadas pesquisadas utilizam uma série de fatores como os vieses cognitivos e emocionais na tomada de decisão que desenvolvem no contexto da Teoria dos Prospectos tais como, o efeito certeza, quando tem maior probabilidade de acontecer; efeito reflexo, apontando ganhos certos e o efeito de isolamento, em que os atuantes podem cometer erro sistemático, tornando a decisão nem sempre racional.

Ao analisar o gênero dos entrevistados, constatou-se que as mulheres possuem uma aversão mais marcante ao risco que os homens. Portanto, na pesquisa replicada, observou-se a não intervenção, no desenvolvimento da racional ilimitada, no processo decisório por meio deste estudo comparativo. Concluiu-se, finalmente, que as perspectivas comportamentais analisadas são influenciadas por sua racionalidade e sua cultura.

Para estudos futuros, sugere-se uma análise comparativa por gerações (faixa etária) para verificar se há diferenças significativas entre as gerações e seus respectivos propensos investidores. 


\section{Referências}

ACKERT, L. F. Traditional and Behavioral Finance In: BAKER, H. Kent; RICCIARDI, Victor. The Psychology of Financial Planning and Investing. NJ : John Wiley \& Sons, 2014. p. 25-41

ARAÚJO, D. R. de; SILVA, C. A. T.. Aversão à Perda nas Decisões de Risco. In:CONGRESSO USP INICIAÇÃO CIENTíFICA EM CONTABILIDADE, 3., 2006, São Paulo. Anais... São Paulo: USP, 2006. p. 1-15 Disponível em: ?<http//:www.eac.fea.usp.br/congresso/anais. htm>. Acesso em: 10 out. 2014.

BARBERIS, N. C.; THALER, R. H.. A Survey of Behavioral Finance. Handbook of the Economics of Finance. Elsevier North Holland, v. 1, parte B, chapter 18, p. $1053-1128,2003$.

BAZERMAN, Max H. Processo Decisório. 5. ed. Rio de Janeiro: Campus, 2004.

CRUZ, L. F. B.; KIMURA, H.; KRAUTER, E.. Finanças comportamentais: investigação do comportamento decisório dos agentes brasileiros de acordo com a teoria do prospecto de Kahneman \& Tversky. In: ASSEMBLEIA DO CONSELHO LATINO - AMERICANO DAS ESCOLAS DE ADMINISTRAÇÃO (CLADEA), XXXVIII, 2003, Lima. Anais... Lima: CLADEA, 2003 (CD-ROM).

FARIAS, P. R. D. de. Finanças comportamentais e o estudo de reações do mercado de capitais através de modelos baseados em agentes. 2009. 116 f. Dissertação (Mestrado em Administração de Empresas). Universidade Presbiteriana Mackenzie, São Paulo, 2009.

VIEIRA, T. R. C.. Finanças Comportamentais: Um estudo sobre - perfil do investidor, o efeito aversão a extremos e o grau de confiança nas decisões de investimentos. 2012, 74 f. Dissertação (Mestrado em Administração). Universidade Federal do Espírito Santo, Vitória, 2002. 
GARCIA, R.; OLAK, P. A. Controladoria Comportamental: constatação empírica de tendências de mudanças no paradigma decisorial quantitativo. In: CONGRESSO USP CONTROLADORIA E CONTABILIDADE, 7, 2007, São Paulo. Anais... São Paulo: USP 2007. p.126. Disponível em: $<$ http//:www.eac.fea.usp.br/congresso/anais.htm>. Acesso em: 15 out. 2014.

KAHNEMAN, D.; TVERSKI, A.. Prospect Theory: an analysis of decision under risk. Econometrica, New York, NY, v 47, n. 2, p. 263-291, Mar. 1979.

KÖBBERLING, V.; WAKKER, P. P. An index of loss aversion. Journal of Economic Theory, Ithaca, NY USA, v. 122, n. 1, p.119-131. Mayo, 2005.

KOCHER, M. G.; SUTTER, M. The decision maker matters: individual versus group behaviour in experimental beauty-contest games. The Economic Journal, Malden MA, USA v. 115, n. 500, p.200-223, Jan. 2005.

MACEDO, M. A. S.; FONTES, P. V. S. Análise do comportamento decisório de analistas contábil-financeiros: um estudo com base na teoria da racionalidade limitada. RCC - Revista Contemporânea de Contabilidade, Florianópolis, v. 6, n. 11, p. 159-186, jan-jun 2009.

MACEDO JR.; J. S. Teoria do prospecto: uma investigação utilizando simulação de investimentos. 2003. 203f. Tese (Doutorado Gestão de Operações) - Universidade Federal de Santa Catariana - UFSC, Florianópolis: UFSC, 2003.

MINETO, C. A. L.. Percepção ao risco e efeito disposição: uma análise experimental da teoria dos prospectos. 2005. 150f. Tese (Doutorado Gestão de Operações) - Universidade Federal de Santa Catariana UFSC, Florianópolis: UFSC, 2005.

OLIVEIRA, E. de; SILVA, S. M. da; SILVA, W. V.da. Finanças comportamentais: um estudo sobre o perfil comportamental do investidor e do propenso investidor In: SEMINÁRIO DE GESTÃO DE NEGÓCIOS 
DA FAE BUSINESS SCHOOL, 2, 2005, Curitiba. Anais.... Curitiba: FAE Business School, 2005. p. 1-15. Disponível em:

<http//:www.fae.edu/publicacoes/pdf/Ilseminario/gestao/gestao_11. pdf>. Acesso em:11 out. 2014.

ROGERS, P.; SECURATO, J. R.; RIBEIRO, K.. Finanças comportamentais no Brasil: um estudo comparativo. Revista de Economia e Administração, São Paulo, v.6, n.1, p. 49-68, jan./mar. 2007.

ROGERS, P.; FAVATO, V.; SECURATO, J. R.. Efeito educação financeira no processo de tomada de decisões em investimentos: um estudo a luz das finanças comportamentais. In: CONGRESSO ANPCONT, 2, 2008, Salvador. Anais... Salvador: ANPCONT, 2008. p. 1-17. Disponível em: <http://www.pablo.prof.ufu.br/artigos/anpcont2.pdf>. Acesso em: 15 out. 2014.

SÁ, Marcelo M.. Decisões financeira em condição de risco por gerente, diretores e firmas brasileiras: uma análise baseada nas finanças comportamentais. 2007. 144 f. Dissertação (Mestrado em Administração de Empresas). Universidade Presbiteriana Mackenzie, São Paulo, 2007.

SAVAGE, L. J. The foundation of statistics. New York: J. Wiley, 1964.

SHEFRIN, H. Behavioralizing Finance. Hanover: Now Pub, 2010.

THALER, R.; MULLAINATHAN, S.. Behavioral Economics. National Bureau of Economic Research. Cambridge, MA, working paper $\mathrm{n}^{\circ}$ 7948, p. 1094-1100, Oct. 2000. Disponível em: <http://www.nber.org/ papers>. Acesso em: 15 out. 2014.

Artigo recebido em: 05/03/2015

Aprovado em: 15/06/2015 